\title{
Assessing the Twenty-First-Century Shift in ENSO Variability in Terms of the Bjerknes Stability Index*
}

\author{
JoKe F. LÜBbecke AND Michael J. MCPhaden \\ NOAA/Pacific Marine Environmental Laboratory, Seattle, Washington
}

(Manuscript received 23 July 2013, in final form 27 November 2013)

\begin{abstract}
A decadal change in the character of ENSO was observed around year 2000 toward weaker-amplitude, higher-frequency events with an increased occurrence of central Pacific El Niños. Here these changes are assessed in terms of the Bjerknes stability index (BJ index), which is a measure of the growth rate of ENSOrelated SST anomalies. The individual terms of the index are calculated from ocean reanalysis products separately for the time periods 1980-99 and 2000-10. The spread between the products is large, but they show a robust weakening of the thermocline feedback due to a reduced thermocline slope response to anomalous zonal wind stress as well as a weakened wind stress response to eastern equatorial Pacific SST anomalies. These changes are consistent with changes in the background state of the tropical Pacific: cooler mean SST in the eastern and central equatorial Pacific results in reduced convection there together with a westward shift in the ascending branch of the Walker circulation. This shift leads to a weakening in the relationship between eastern Pacific SST and longitudinally averaged equatorial zonal wind stress. Also, despite a steeper mean thermocline slope in the more recent period, the thermocline slope response to wind stress anomalies weakened due to a smaller zonal wind fetch that results from ENSO-related wind anomalies being more confined to the western basin. As a result, the total BJ index is more negative, corresponding to a more strongly damped system in the past decade compared to the 1980s and 1990s.
\end{abstract}

\section{Introduction}

The El Niño-Southern Oscillation (ENSO) is a coupled ocean-atmosphere phenomenon originating in the tropical Pacific associated with strong year-to-year fluctuations in sea surface temperature (SST) and surface zonal winds. It is the dominant mode of variability on interannual time scales in the tropics and its teleconnections affect climate around the world (McPhaden et al. 2006). Understanding the mechanisms behind ENSO and changes in ENSO behavior is thus of great socioeconomic importance because of its impacts on climate sensitive areas of human endeavor.

A change in ENSO variability has been observed over the past decade. After 1999/2000, the amplitude of the ENSO cycle weakened while the frequency increased

\footnotetext{
* Pacific Marine Environmental Laboratory Contribution Number 4040 .

Corresponding author address: Joke F. Lübbecke, NOAA/ PMEL, 7600 Sand Point Way NE, Seattle, WA 98115.

E-mail: joke.luebbecke@noaa.gov
}

(McPhaden 2012; Hu et al. 2013). This change can be clearly seen in time series of SST anomalies averaged over the Niño-3 region $\left(5^{\circ} \mathrm{S}-5^{\circ} \mathrm{N}, 150^{\circ}-90^{\circ} \mathrm{W}\right.$; Fig. 1$)$. While $5 \mathrm{El}$ Niño events occurred in the $20 \mathrm{yr}$ between 1980 and 1999 (on average one every 4 yr) with amplitudes of up to $3.5^{\circ} \mathrm{C}, 4 \mathrm{El}$ Niños occurred in the decade between 2000 and 2010 (on average one every $2.5 \mathrm{yr}$ ) but with amplitudes well below $2^{\circ} \mathrm{C}$ [the number of events according to the classification by the National Oceanic and Atmospheric Administration (NOAA) National Weather Service (NWS) Climate Prediction Center (CPC)]. ENSO forecast skill has likewise decreased (Barnston et al. 2012) due in part to a weakened relationship between upper ocean heat content and SST in the eastern equatorial Pacific (McPhaden 2012; Horii et al. 2012). Also, more "Modoki" or central Pacific (CP) El Niños have occurred with the locus of warm SST anomalies shifted westward toward the date line leading to changes in teleconnection patterns and climate impacts (e.g., Larkin and Harrison 2005; Ashok et al. 2007). This longitudinal shift is illustrated by composites of SST, wind stress, and thermocline depth for the DecemberFebruary mean of El Niño years for the time periods 


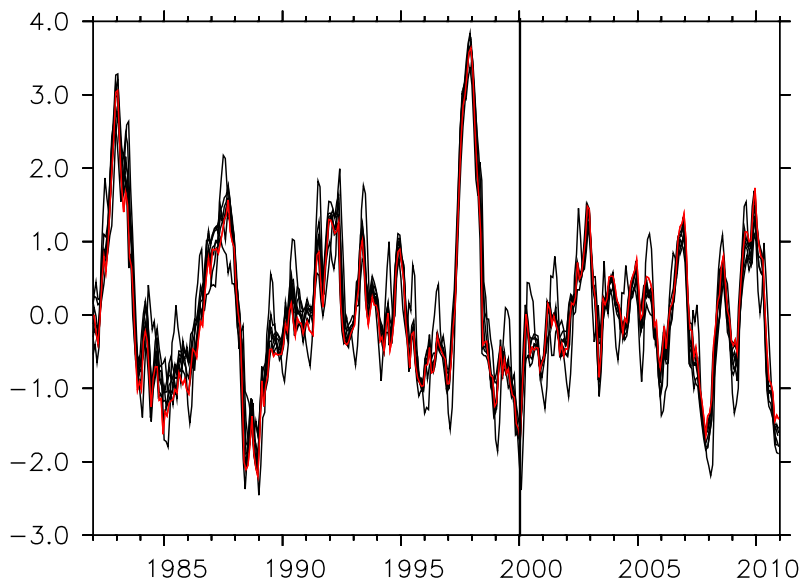

FIG. 1. Time series of Niño-3 SSTA $\left({ }^{\circ} \mathrm{C}\right)$ from Reynolds (red line) and the eight reanalysis products (black lines). We make no effort to distinguish the different reanalysis SSTA time series since they are virtually identical. Five El Niño events occurred between 1980 and 1999, and four occurred between 2000 and 2010.

1980-99 and 2000-10 [Fig. 2; cf. McPhaden et al. (2011, their Fig. 2)]. Central Pacific El Niños tend to be weaker on average than the canonical eastern Pacific (EP) El Niños (e.g., Giese and Ray 2011), though the 2009/10 CP El Niño was unusually strong (Lee and McPhaden 2010).

The decadal changes in ENSO character have been accompanied by a change in the background conditions in the tropical Pacific toward stronger trade winds and a steeper east-west slope of the thermocline along the equator (McPhaden et al. 2011; Kumar and $\mathrm{Hu}$ 2013; Chung and Li 2013). Decadal modulations in ENSO characteristics have been linked to changes in the mean background state of the tropical Pacific in idealized studies (e.g., Battisti and Hirst 1989; Wakata and Sarachik
1991). An and Wang (2000) find that the change of the ENSO frequency in the late 1970s was accompanied by changes in the location and intensity of zonal wind stress. With respect to the recent change in ENSO variability, $\mathrm{Hu}$ et al. (2013) link the weakened ENSO cycle to changes in the mean state by suggesting that enhanced trade winds and steeper thermocline slope restrict the eastward migration of warm water from the western equatorial Pacific. From analysis of a 500-yr coupled model simulation, Choi et al. (2011) also find that a regime in which CP El Niños are occurring frequently is associated with strong trade winds and a strong SST gradient in the equatorial Pacific. Using reanalyses and observational data for 1980-2010 as well as idealized numerical experiments Chung and Li (2013) likewise suggest that the high occurrence of $\mathrm{CP} \mathrm{El}$ Niños is associated with a more La Niña-like background state. They find that while the precipitation and wind sensitivity to an SST anomaly are larger for CP El Niños, the oceanic response to that wind forcing is weaker for $\mathrm{CP}$ El Niños because of the westward shift of SST and wind stress anomalies. The sensitivity of ENSO to changes in stratification has been addressed by Thual et al. (2011, 2013) who find that a decadal modulation of ENSO stability is significantly correlated to decadal changes of central Pacific mean stratification in some coupled general circulation models (CGCMs).

Based on the recharge oscillator framework for ENSO (Jin 1997), Jin et al. (2006) developed the socalled Bjerknes stability index (hereafter BJ index) to describe ocean-atmosphere interactions in the tropical Pacific. This index, with positive values indicating an unstable cycle and negative values indicating a damped cycle, has been used successfully to assess the stability of ENSO in various coupled models (Kim and Jin 2011a,b).
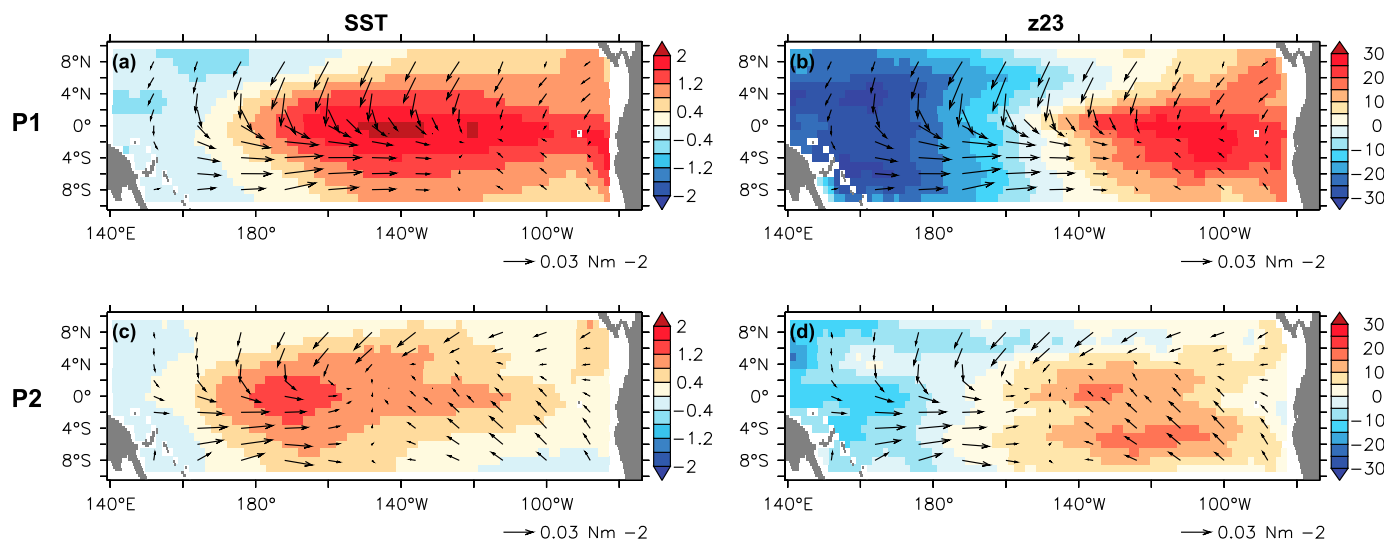

FIG. 2. Ensemble mean composites from the eight reanalysis products of (a),(c) El Niño year December-February (DJF) SST anomalies $\left({ }^{\circ} \mathrm{C}\right)$ and (b),(d) depth of the $23^{\circ} \mathrm{C}$ isotherm $(\mathrm{z} 23)$ anomalies $(\mathrm{m})$ with wind stress anomalies $\left(\mathrm{N} \mathrm{m}^{-2}\right)$ overlaid for the corresponding time period; (a),(b) 1980-99 and (c),(d) 2000-10. 
Mean advection and thermal damping make negative contributions to the index while positive contributions come from the zonal advective, Ekman, and thermocline feedbacks. Kug et al. (2009) found that while EP El Niños are driven mainly by the thermocline feedback, the zonal advective feedback plays an important role for CP El Niños. Ren and Jin (2013) found, however, that the thermocline feedback makes the largest contribution to the growth rate for both ENSO types while the zonal advective feedback was more important for the transition from one phase of ENSO to the next. In this study we will use the Bjerknes stability index to assess the changes in ENSO feedbacks between 1980-99 and 2000-10. These time periods, especially the later one, are relatively short. To obtain robust results, we will therefore use an ensemble of ocean reanalysis products. Special attention is given to the role of the thermocline feedback and its relation to changes in background conditions.

The remainder of this paper is organized as follows: the $\mathrm{BJ}$ index is introduced in section 2. In section 3 we briefly describe the reanalysis products and observational data. The results for the two time periods and their relation to the mean background state are presented in section 4 . The results are summarized and discussed in section 5 .

\section{BJ index}

Jin et al. (2006) derived the Bjerknes coupled stability index based on the recharge oscillator framework for ENSO (Jin 1997). The BJ index $I_{B J}$ is the growth rate of SST anomalies in the recharge oscillator model. It can be interpreted as a measure for the stability of the coupled ENSO mode. We here use the BJ index formulation as applied in Lübbecke and McPhaden (2013), following Jin et al. (2006) with modifications from Stein et al. (2010) and Kim and Jin (2011b), namely,

$$
\begin{aligned}
& 2 I_{\mathrm{BJ}}=-\left(\frac{\langle\bar{u}\rangle_{E}}{L_{x}}+\frac{\langle-2 y \bar{v}\rangle_{E}}{L_{y}^{2}}+\frac{\langle\bar{w}\rangle_{E}}{H_{m}}\right)-\alpha+\mu_{a} \beta_{u}\left\langle\frac{-\partial \bar{T}}{\partial x}\right\rangle_{E} \\
& +\mu_{a} \beta_{w}\left\langle\frac{-\partial \bar{T}}{\partial z}\right\rangle_{E}+\mu_{a} \beta_{h}\left\langle\frac{H(\bar{w}) \bar{w}}{H_{m}} a_{h}\right\rangle_{E},
\end{aligned}
$$

where $u, v, w$ are the zonal ( $x$ direction), meridional ( $y$ direction), and vertical ( $z$ direction) velocity, respectively; and $T$ represents sea surface temperature. Here \langle\rangle$_{E}$ denotes a volume average over the Niño-3 region and from the surface to the base of the mixed layer and the overbar denotes the climatological time mean. The terms $L_{x}$ and $L_{y}$ are the zonal and meridional extent of the averaging region, and $y$ is the distance from the equator. The step function $H(x)$ ensures that only upstream vertical advection is taken into account. Here $H_{m}$ represents the effective depth for vertical advection.

All five terms on the right-hand side of Eq. (1) describe a feedback of an SST anomaly in the eastern equatorial Pacific on itself. The first two terms represent dynamical and thermal damping that make negative contributions. The thermal damping $\alpha$ describes the relation between SST anomalies and anomalous heat flux and is the dominant negative damping term (Kim and Jin 2011a; Lübbecke and McPhaden 2013). The dynamical damping describes the effect of zonal and meridional currents as well as the mean upwelling. The last three terms represent positive feedbacks that act to enhance the SST anomaly and thus make positive contributions to the BJ index. From left to right they are the zonal advective, Ekman, and thermocline feedback. They all contain the parameter $\mu_{a}$ that describes the basinwide zonal wind stress $\left(5^{\circ} \mathrm{S}-5^{\circ} \mathrm{N}, 160^{\circ} \mathrm{E}-90^{\circ} \mathrm{W}\right)$ response to an SST anomaly in the eastern equatorial basin $\left(5^{\circ} \mathrm{S}-5^{\circ} \mathrm{N}, 150^{\circ}-90^{\circ} \mathrm{W}\right)$. The zonal advective feedback describes the effect of zonal currents forced by this anomalous zonal wind stress $\left(\beta_{u}\right)$ acting on the mean zonal temperature gradient. The Ekman feedback describes the effect of anomalous wind-driven upwelling $\left(\beta_{w}\right)$ acting on the mean vertical temperature gradient. The thermocline feedback describes the effect of changes in the equatorial thermocline slope forced by anomalous basinwide zonal wind stress $\left(\beta_{h}\right)$ on subsurface $\left(a_{h}\right)$ and subsequently, via mean upwelling, surface temperatures. The thermocline slope is calculated as the difference between the depth of the $23^{\circ} \mathrm{C}$ isotherm in the eastern $\left(5^{\circ} \mathrm{S}-5^{\circ} \mathrm{N}, 150^{\circ}-90^{\circ} \mathrm{W}\right)$ and western $\left(5^{\circ} \mathrm{S}-5^{\circ} \mathrm{N}, 160^{\circ} \mathrm{E}-150^{\circ} \mathrm{W}\right)$ equatorial Pacific. The parameters $\alpha, \mu_{a}, a_{h}, \beta_{u}, \beta_{w}$, and $\beta_{h}$ are estimated from linear regression using balance equations derived from the recharge oscillator theory (Jin 1997), as shown in Jin et al. (2006), Kim and Jin (2011a,b), and Lübbecke and McPhaden (2013).

\section{Ocean reanalysis products}

Monthly fields of ocean temperature and velocity are taken from eight ocean reanalysis products. Zonal wind stress and heat flux anomalies are taken from the atmospheric fields that were used as forcing for the corresponding ocean models. Ocean reanalyses provide an ocean hindcast based on ocean general circulation models forced by atmospheric forcing fluxes in which a variety of observational ocean temperature, salinity, and sea level anomalies data have been assimilated. The 
reanalysis products used here include two versions of the Simple Ocean Data Assimilation (SODA; Carton and Giese 2008), namely SODA 2.0.2-4 (referred to as SODA 1) and the historical run SODA 2.2.4 (referred to as SODA 2). In addition we use the National Centers for Environmental Prediction (NCEP) Global Ocean Data Assimilation System (GODAS) from the NOAA/NWS/ CPC (Behringer and Xue 2004), two versions-ocean analysis/reanalysis system (ORA-S3; Balmaseda et al. 2008) and ORA-S4 (Balmaseda et al. 2013) —of the ocean analysis system from the European Centre for Medium-Range Weather Forecasts (ECMWF), the ensemble coupled data assimilation product (ECDA) from the Geophysical Fluid Dynamics Laboratory (GFDL; Zhang et al. 2007), the ocean reanalysis product from the Instituto Nationale di Geografisica Vulcanologia (INGV OI5; Masina et al. 2011), and the latest version of the German Estimating the Circulation and Climate of the Ocean (ECCO) from Hamburg University (GECCO2; Köhl and Stammer 2008). Detailed information about the ocean reanalysis datasets can be found in the Ocean Synthesis Directory of the Integrated Climate Data Center at Hamburg University (http://icdc.zmaw.de/easy_init_ocean.html).

For GODAS, ORA-S4, and GFDL ECDA no vertical velocity fields are provided. Vertical velocities are therefore calculated from mass continuity for these reanalyses. All products are analyzed for 1980 to 2010 with the exception of SODA 1 (available up to 2007) and GECCO2 (available up to 2009). All time series are detrended and interannual anomalies are calculated by subtracting a repeated mean seasonal cycle based on individual model climatologies.

Additionally we use observational and atmospheric reanalysis datasets to calculate the index terms $\alpha, \beta_{h}$, and $\mu_{a}$ independently as well as assess changing background conditions in the tropical Pacific. In particular, we use monthly fields of NOAA optimum interpolation SST (Reynolds et al. 2002) derived from blended in situ and satellite observations with a spatial resolution of $1^{\circ}$. Subsurface temperatures for the tropical Pacific, based on data from moored buoys, expendable bathythermographs and Argo floats, are available from the Bureau of Meteorology Research Center and the Centre for Australian Weather and Climate Research (BMRC/CAWCR; Smith 1995) at a horizontal resolution of $1^{\circ}$ latitude $\times 2^{\circ}$ longitude. Outgoing longwave radiation (OLR) data at $2.5^{\circ}$ horizontal resolution are obtained from NOAA/ Office of Oceanic and Atmospheric Research/Earth System Research Laboratory/Physical Sciences Division (NOAA/OAR/ESRL/PSD, www.esrl.noaa.gov/psd/; Liebmann and Smith 1996). For wind stress and surface heat flux we use the Interim ECMWF Re-Analysis
(ERA-Interim) monthly mean fields averaged from daily means from the ECMWF data portal (http://data-portal. ecmwf.int/; Dee et al. 2011).

\section{Results}

\section{a. Differences in BJ index terms between 1980-99 and 2000-10}

The individual terms of the BJ index, calculated separately for the time periods 1980-99 (P1) and 2000-10 (P2) from the various reanalysis products, as well as the ensemble means of these terms computed from all reanalysis products, are shown in Fig. 3. The individual regression coefficients are summarized in Table 1. A positive BJ index corresponds to an unstable system and a negative index to a damped system. Error bars are displayed for one standard error. The standard error of the ensemble means is calculated as the standard deviation of the products (the ensemble spread) divided by the square root of the number of ensemble members. Consistent with the observed weaker-amplitude ENSO cycle, the total $\mathrm{BJ}$ index is more negative (i.e., corresponding to a more strongly damped system), during P2 in all products except for GECCO2. Regarding the negative feedback terms, the thermal damping is dominant over the dynamical damping with values of about $-2 \mathrm{yr}^{-1}$ in all products with the exception of GECCO2 that shows a weaker thermal damping. There is no clear trend in thermal damping between the two time periods. Some products show a slight reduction, others a small increase. The observational value from Reynolds SST and ERA-Interim heat flux also stays almost constant with $2.12 \mathrm{yr}^{-1}$ in $\mathrm{P} 1$ and $2.17 \mathrm{yr}^{-1}$ in $\mathrm{P} 2$ (not shown). The ensemble averages for the two time periods lie close together with overlapping error bars. The spread among the different products reflects the uncertainty of heat flux variations in the eastern equatorial Pacific. As shown by Praveen Kumar et al. (2012), there are large differences between heat flux products with regard to interannual variability over the cold tongue in the eastern Pacific. There is also no consistent change in the dynamical damping that is dominated by the upwelling term (not shown) and on average amounts to about $-0.45 \mathrm{yr}^{-1}$.

With respect to the positive feedback terms, the thermocline feedback plays the most important role, regarding both its contribution to the total $\mathrm{BJ}$ index and the change from P1 to P2. It is the dominant positive feedback in all products in P1 (ensemble average of $0.84 \mathrm{yr}^{-1}$ ) and in most products for P2 (ensemble average of $0.51 \mathrm{yr}^{-1}$ ). The zonal advective and Ekman feedbacks are much smaller on average (around $0.3 \mathrm{yr}^{-1}$ for the zonal advective feedback and $0.2 \mathrm{yr}^{-1}$ for the 

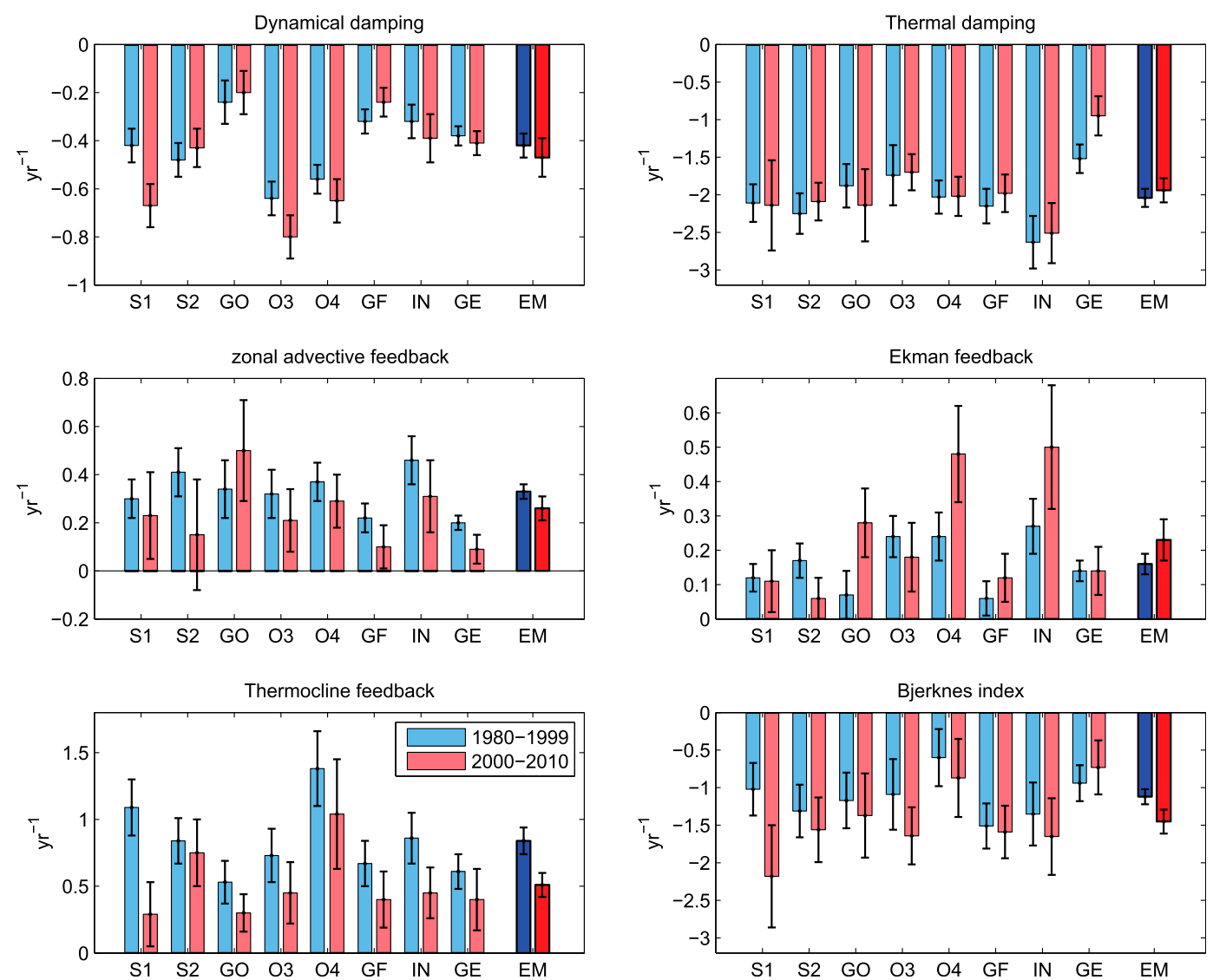

FIG. 3. Individual components of the Bjerknes index and total index from eight reanalysis products (S1: SODA2.0.2-4, S2: SODA-2.2.4, GO: GODAS, O3: ORA-S3, O4: ORA-S4, GF: GFDL ECDA, IN: INGV OI5, and GE: GECCO2) and their ensemble mean (EM) calculated separately for 1980 to 1999 (blue) and 2000 to 2010 (red). Error bars show one standard error.

Ekman feedback), but can be as important as the thermocline feedback in some of the products, especially in $\mathrm{P} 2$. No consistent change can be seen from P1 to P2 in the Ekman and zonal advective feedbacks. While in some products these feedbacks become more important in $\mathrm{P} 2$ relative to P1 (e.g., Ekman feedback in INGV OI5 and ORA-S4, both feedbacks in GODAS), in others they are reduced (e.g., zonal advective feedback in GECCO2, both feedbacks in SODA 2). As a result, the difference between the ensemble averages of these two positive

TABLE 1. BJ index regression coefficients for the reanalysis products, their ensemble mean (EM), and ensemble standard error (ESE), separately for 1980-99 (P1) and 2000-10 (P2).

\begin{tabular}{|c|c|c|c|c|c|c|c|c|c|c|}
\hline \multirow{2}{*}{$\begin{array}{c}\text { Reanalysis } \\
\text { product }\end{array}$} & \multicolumn{2}{|c|}{$\mu_{a}\left(10^{-2} \mathrm{~N} \mathrm{~m}^{-2} \mathrm{~K}^{-1}\right)$} & \multicolumn{2}{|c|}{$\beta_{u}\left(\mathrm{~m} \mathrm{~s}^{-1} \mathrm{~N}^{-1} \mathrm{~m}^{-2}\right)$} & \multicolumn{2}{|c|}{$\beta_{w}\left(10^{-5} \mathrm{~m} \mathrm{~s}^{-1} \mathrm{~N}^{-1} \mathrm{~m}^{-2}\right)$} & \multicolumn{2}{|c|}{$\beta_{h}\left(\mathrm{~m} \mathrm{~N}^{-1} \mathrm{~m}^{-2}\right)$} & \multicolumn{2}{|c|}{$a_{h}\left(10^{-2} \mathrm{~K} \mathrm{~m}^{-1}\right)$} \\
\hline & $\mathrm{P} 1$ & $\mathrm{P} 2$ & $\mathrm{P} 1$ & $\mathrm{P} 2$ & $\mathrm{P} 1$ & $\mathrm{P} 2$ & $\mathrm{P} 1$ & $\mathrm{P} 2$ & $\mathrm{P} 1$ & $\mathrm{P} 2$ \\
\hline SODA1 & 0.63 & 0.33 & 9.5 & 13.1 & 6.1 & 8.8 & 2245 & 1185 & 6.0 & 6.2 \\
\hline SODA2 & 0.65 & 0.58 & 12.5 & 5.2 & 7.6 & 2.5 & 1825 & 1638 & 6.4 & 6.6 \\
\hline GODAS & 0.47 & 0.48 & 13.3 & 15.5 & 3.7 & 13.0 & 2369 & 1630 & 4.7 & 4.3 \\
\hline ORA-S3 & 0.58 & 0.37 & 11.5 & 11.5 & 8.8 & 8.6 & 2010 & 1491 & 7.0 & 7.9 \\
\hline ORA-S4 & 0.73 & 0.59 & 11.9 & 10.9 & 7.2 & 16.0 & 2032 & 1698 & 7.2 & 7.7 \\
\hline GFDL & 0.53 & 0.41 & 9.4 & 5.3 & 2.6 & 6.1 & 1992 & 1558 & 6.5 & 7.0 \\
\hline INGV & 0.68 & 0.62 & 14.0 & 9.6 & 8.0 & 14.5 & 2107 & 1469 & 5.6 & 5.2 \\
\hline GECCO2 & 0.56 & 0.46 & 12.8 & 6.3 & 6.8 & 8.4 & 1975 & 1721 & 6.4 & 5.9 \\
\hline $\mathrm{EM} \pm \mathrm{ESE}$ & $\begin{array}{l}0.60 \\
\quad( \pm 0.03)\end{array}$ & $\begin{array}{l}0.48 \\
\quad( \pm 0.04)\end{array}$ & $\begin{array}{l}11.9 \\
\quad( \pm 0.6)\end{array}$ & $\begin{array}{l}9.7 \\
( \pm 1.3)\end{array}$ & $\begin{array}{l}6.4 \\
\quad( \pm 0.8)\end{array}$ & $\begin{array}{l}9.7 \\
( \pm 1.5)\end{array}$ & $\begin{array}{l}2069 \\
\quad( \pm 60)\end{array}$ & $\begin{array}{l}1549 \\
\quad( \pm 61)\end{array}$ & $\begin{array}{l}6.2 \\
( \pm 0.3)\end{array}$ & $\begin{array}{l}6.4 \\
\quad( \pm 0.4)\end{array}$ \\
\hline
\end{tabular}



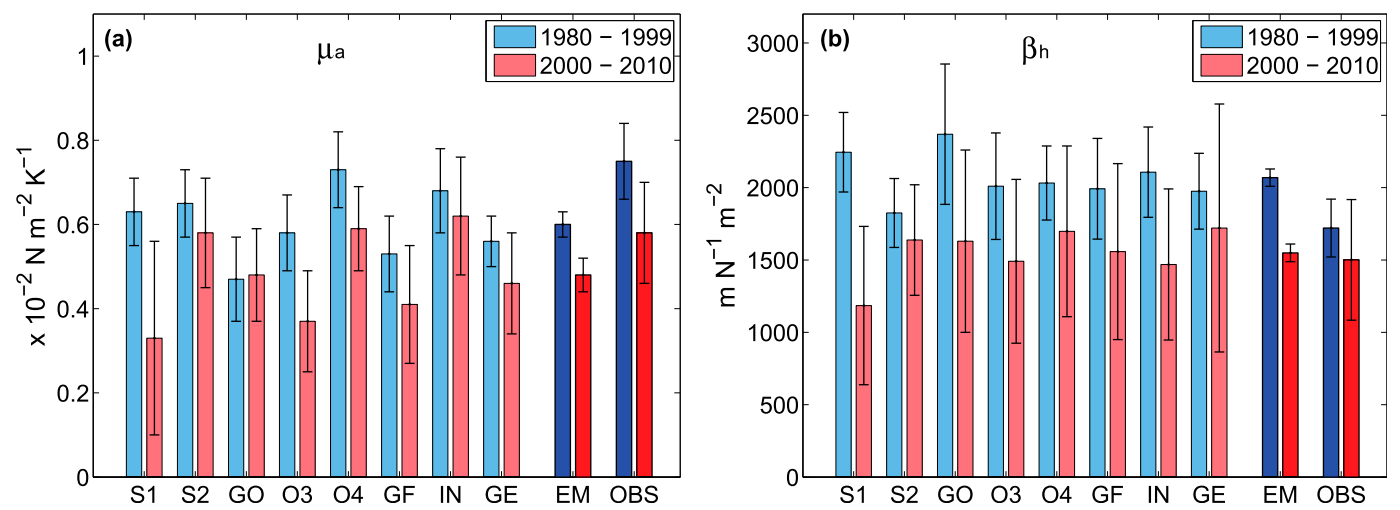

FIG. 4. (a) Basinwide zonal wind stress response to eastern equatorial SST anomalies $\left(\mu_{a}\right)$ and (b) thermocline slope response to zonal wind stress anomalies $\left(\beta_{h}\right)$ from eight reanalysis products (S1: SODA-2.0.2-4, S2: SODA2.2.4, GO: GODAS, O3: ORA-S3, O4: ORA-S4, GF: GFDL ECDA, IN: INGV OI5, and GE: GECCO2), their ensemble mean (EM), and observations (OBS) calculated separately for 1980-99 (P1, blue) and 2000-10 (P2, red). Error bars show one standard error.

feedbacks for P1 and P2 do not exceed one standard error. By contrast, there is a robust weakening of the thermocline feedback in all products during P2 leading to clearly separated ensemble averages for the two time periods. We thus conclude that the robust change in the total $\mathrm{BJ}$ index can be mainly attributed to the weakening of the thermocline feedback. This is consistent with results by Borlace et al. (2013) who find that multidecadal modulations of ENSO amplitude as expressed by the BJ index are controlled by the thermocline feedback in their 1000-yr model integration.

Which part of the thermocline feedback is responsible for the weakening? The thermocline feedback term is defined by four parameters $\left[\mu_{a}, \beta_{h}, a_{h}\right.$, and $\left.H(w) w / H_{m}\right]$. Here $\mu_{a}$ describes the response of the basinwide equatorial zonal wind stress to SST anomalies in the eastern equatorial Pacific and is estimated from linear regression between equatorial Pacific zonal wind stress $\left(5^{\circ} \mathrm{S}-5^{\circ} \mathrm{N}\right.$, $160^{\circ} \mathrm{E}-90^{\circ} \mathrm{W}$ ) and Niño-3 SST anomalies. The $\beta_{h}$ describes the thermocline slope response to anomalous zonal wind stress forcing and is estimated from the regression between the difference in thermocline depth anomalies in the eastern (Niño-3) and western (Niño-4) equatorial Pacific and the basinwide equatorial zonal wind stress anomalies. The $a_{h}$ describes the effect of eastern Pacific thermocline depth changes on local subsurface temperatures. These subsurface temperature anomalies are upwelled to the surface to impact SST by the mean upward vertical velocity at the base of the mixed layer $H(w) w / H_{m}$.

Comparison between the two time periods shows that the main difference stems from the parameters $\mu_{a}$ and $\beta_{h}$ while there is no substantial change in $a_{h}$, and $H(w) w / H_{m}$. Figure 4 shows $\mu_{a}$ and $\beta_{h}$ for P1 and P2 for the eight reanalysis products and their ensemble mean, as well as for the observations. The numerical values are also listed in Table 1. With the exception of GODAS, $\mu_{a}$ is smaller in all products in the more recent time period with a reduction of $20 \%$ on average, which is very similar to the observations. The individual values of the reduction range between $0 \%$ (GODAS) and almost $50 \%$ (SODA 1). The spread between the products is smaller for $\beta_{h}$, which is weakened in all cases by $10 \%-30 \%$, except that in SODA 1 the reduction is more than $50 \%$. In contrast, $a_{h}$ stays almost constant in most of the reanalysis products (Table 1 ) with a change of more than $10 \%$ from $\mathrm{P} 1$ to $\mathrm{P} 2$ found only in ORA-S3 (+13\%). The same is true for $H(w) w / H_{m}$ with changes of more than $10 \%$ only for GODAS $(-13 \%)$ and ORA-S3 (+15\%). Thus, the combined reduction in both the zonal wind stress response to SST anomalies and the thermocline slope response to these wind stress anomalies leads to an overall weakening of the thermocline feedback.

\section{b. Background state changes}

Why did both $\mu_{a}$ and $\beta_{h}$ decrease in the first decade of the twenty-first century? To address this question we examine changes in the background state of the equatorial Pacific over the past 30 years (Fig. 5). Consistent with the observational results of McPhaden et al. (2011) and Chung and $\mathrm{Li}$ (2013) we find in the reanalysis products that compared to 1980-99, the most recent time period exhibits enhanced easterly zonal wind stress, especially in the west, accompanied by warming in the west and cooling in the east and along the South American coast (Fig. 5c). The thermocline (as measured by the depth of the $23^{\circ} \mathrm{C}$ isotherm) is deeper in the west and shallower in the east corresponding to an increased thermocline slope (Fig. 5d). Thus contrary to the suggestion by Yeh et al. (2009) that the thermocline 

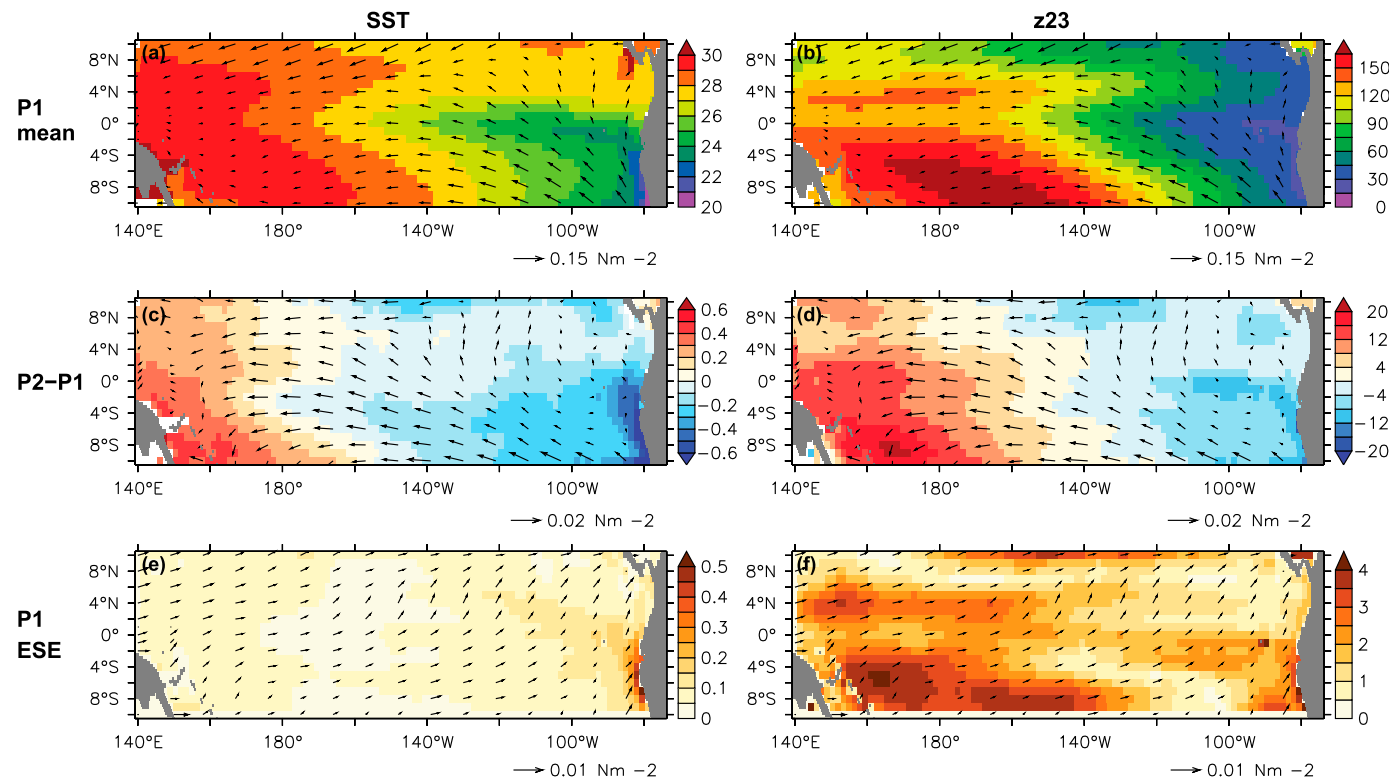

FIG. 5. Ensemble means from the eight reanalysis products for (a) SST $\left({ }^{\circ} \mathrm{C}\right)$ and (b) depth of the $23^{\circ} \mathrm{C}$ isotherm $\mathrm{z} 23(\mathrm{~m})$ with wind stress $\left(\mathrm{N} \mathrm{m}^{-2}\right)$ overlaid for the time period 1980-99. Ensemble mean difference between 2000-10 and 1980-99 for (c) SST $\left({ }^{\circ} \mathrm{C}\right)$ and $(\mathrm{d})$ depth of the $23^{\circ} \mathrm{C}$ isotherm $\mathrm{z} 23(\mathrm{~m})$ with wind stress differences $\left(\mathrm{N} \mathrm{m}^{-2}\right)$ overlaid. Ensemble standard error for (e) SST and (f) z23 and wind stress overlaid for the time period 1980-99.

feedback should weaken due to a flattened mean eastwest thermocline slope, we find that the thermocline feedback weakened in face of a stronger mean east-west thermocline slope in the past decade. The agreement between the reanalysis products is high for SST while there is more spread for thermocline depth and wind stress (Figs. 5e,f). Using a threshold of one standard error, differences between the two time periods are significant over the whole region for SST and z23 and in the southern and western part of the basin for wind stress (i.e., there is a robust strengthening of the southeasterly trades).

SST affects wind stress via its impact on convection and rainfall, so to understand changes in the relation between SST anomalies and anomalous zonal wind stress $\left(\mu_{a}\right)$ we turn to changes in OLR. OLR is a proxy for deep convection with decreased OLR corresponding to increased deep convection. Cooler mean SSTs in the east during the more recent time period result in weaker mean convection (i.e., reduced deep cloudiness and enhanced mean OLR; Figs. 6a,c,e). Figures $6 \mathrm{~b}$,d shows a pointwise regression of OLR anomalies onto SST anomalies indicating that the time-varying SST-OLR relationship is substantially weaker in the more recent period in the eastern equatorial Pacific because of the cooler mean SSTs there after 2000. In the far west near the equator, the connection strengthened (Fig. 6f), suggesting
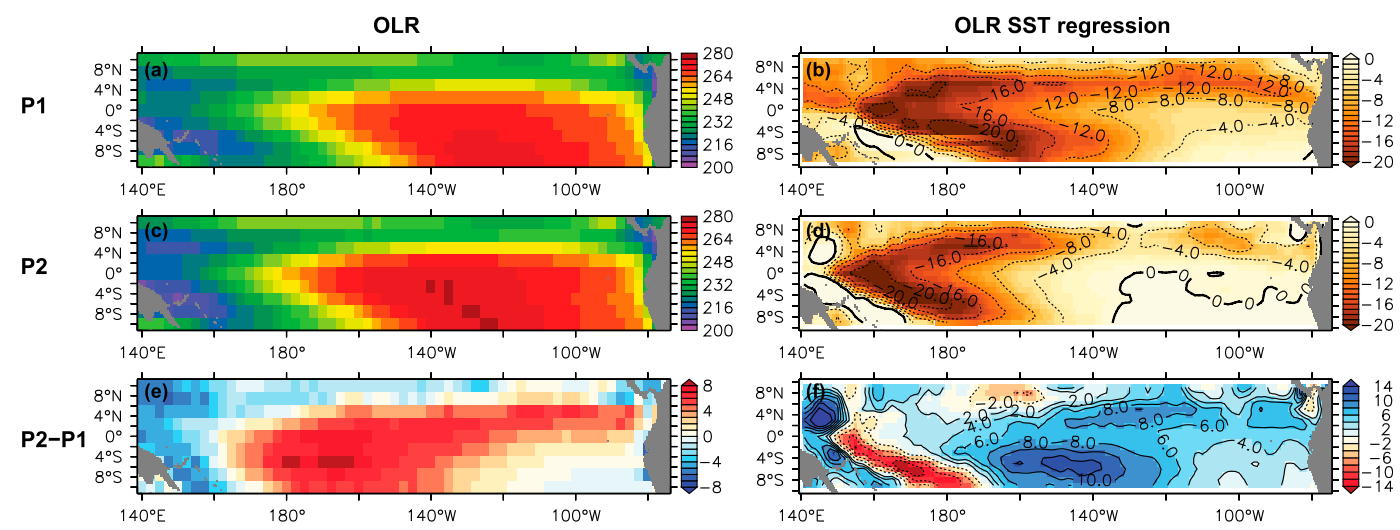

FIG. 6. (a),(c),(e) Mean OLR ( $\mathrm{W} \mathrm{m}^{-2}$ ) and (b),(d),(f) OLR anomalies regressed pointwise onto Reynolds SST anomalies $\left(\mathrm{W} \mathrm{m}^{-2} \mathrm{~K}^{-1}\right)$ for (a),(b) P1; (c),(d) P2; and (e),(f) difference between P2 and P1. 

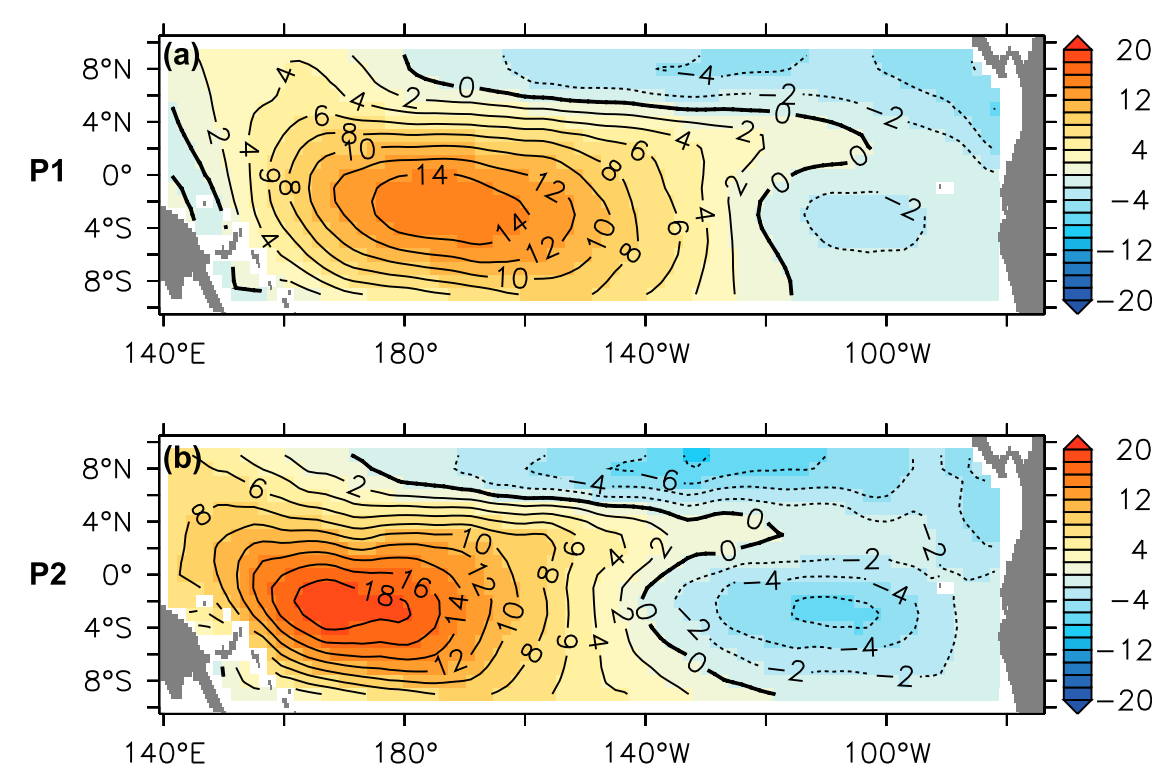

FIG. 7. Ensemble mean from the eight reanalysis products of zonal wind stress anomalies regressed onto Niño-3 SST anomalies $\left(10^{-3} \mathrm{~N} \mathrm{~m}^{-2} \mathrm{~K}^{-1}\right)$ for (a) P1 and (b) P2.

a southwestward displacement of the South Pacific convergence zone (SPCZ) and a northward displacement of the intertropical convergence zone (ITCZ) in the Northern Hemisphere as would be expected for colder mean equatorial SSTs in the eastern and central basin. The shift in the mean OLR together with the modified pattern in the SST-OLR relationship (Fig. 6) indicates a westward shift of the ascending branch of the Walker circulation. This shift has consequences for the wind stress response. The zonal wind stress regression onto Niño-3 SST anomalies shows a stronger maximum amplitude in the more recent period but is more confined to the western part of the basin while the eastern part shows a response of opposite sign (Fig. 7). Since the zonal wind stress response to SST anomalies $\mu_{a}$ is calculated using the basin-averaged wind stress anomalies, it is smaller during P2 because of the significant sign change in wind stress sensitivity as a function of longitude.

The westward confinement of the zonal wind stress response to SST anomalies in the more recent period (Fig. 7b) is also the reason behind the weakening of $\beta_{h}$. As illustrated in the composites of SST, thermocline depth, and wind stress anomalies in El Niño years from the reanalysis products [Fig. 2, see also Fig. 2 in McPhaden et al. (2011) for composites from observations] in the 1980s and 1990s, wind anomalies associated with El Niño events on average extended across the basin while they were concentrated in the western half of the basin after 2000. This was associated with a much weaker tilt of the thermocline for P2 El Niño events (Fig. 2d). We attribute this weakening to the smaller zonal wind fetch resulting from SST anomalies confined to the central Pacific (Fig. 2c). On the equator, wind stress forcing balances the zonal pressure gradient vertically integrated from the depth of the thermocline to the surface [see Clark et al. 2007, their Eq. (1.4)] and the thermocline slope response is proportional to the zonal integral of the wind to the west of an observation point (Kessler and McPhaden 1995). As ENSO-related wind anomalies are weaker and more confined to the western basin during 2000-10, the zonal integral of zonal wind stress anomalies along the equator is reduced, leading to a weaker thermocline slope response.

\section{c. BJ index for Niño-3+}

The BJ index was developed as a diagnostic for eastern Pacific ENSO events and is therefore less sensitive to changes in the central Pacific. To account for the eastwest shift in the location of maximum anomalies we have also calculated $\mathrm{BJ}$ index terms using a modified region, namely "Niño-3+" $\left(5^{\circ} \mathrm{S}-5^{\circ} \mathrm{N}, 180^{\circ}-90^{\circ} \mathrm{W}\right)$ that encompasses SST anomalies associated with both CP and EP El Niños. The longitudinal boundaries of the western box for the BJ index calculation have been changed accordingly to $160^{\circ} \mathrm{E}-160^{\circ} \mathrm{W}$. Based on the Niño-3+ region, the wind response to SST anomalies $\left(\mu_{a}\right)$ and the thermocline slope response to wind stress changes $\left(\beta_{h}\right)$ are reduced as for Niño-3 in all reanalysis products except for SODA2. The ensemble averages decrease from $0.66 \pm 0.04 \times 10^{-2} \mathrm{~N} \mathrm{~m}^{-2} \mathrm{~K}^{-1}$ to $0.51 \pm$ $0.03 \times 10^{-2} \mathrm{~N} \mathrm{~m}^{-2} \mathrm{~K}^{-1}$ for $\mu_{a}$ and from $1763 \pm 66 \mathrm{~m} \mathrm{~N}^{-1} \mathrm{~m}^{-2}$ to $1464 \pm 58 \mathrm{~m} \mathrm{~N}^{-1} \mathrm{~m}^{-2}$ for $\beta_{h}$. As a result, the thermocline 
feedback also weakens from P1 to P2 in most of the ocean reanalysis products, though the difference is less significant than for the Niño-3 region with ensemble averages of $0.61 \pm 0.08 \mathrm{yr}^{-1}$ for $\mathrm{P} 1$ and $0.54 \pm 0.09 \mathrm{yr}^{-1}$ for P2. Results for the zonal advective feedback based on Niño-3+ indicate absolute values $\left(0.53 \pm 0.04 \mathrm{yr}^{-1}\right.$ for $\mathrm{P} 1$ and $0.43 \pm 0.05 \mathrm{yr}^{-1}$ for $\mathrm{P} 2$ ) about $50 \%$ larger than for the Niño-3 region, reflecting the greater importance of the zonal advective feedback in the central Pacific. The zonal advective feedbacks are still smaller than the thermocline feedbacks though and they decrease from $\mathrm{P} 1$ to $\mathrm{P} 2$ as for the Niño-3 calculation. We conclude that although our results are biased toward eastern Pacific SST variability by the nature of how the BJ index is formulated, they appear to hold for a wider region that includes the central Pacific.

\section{Summary and discussion}

In this study we assessed the decadal change in ENSO character over the past 30 years in terms of the Bjerknes stability index. Using a variety of ocean reanalysis products we found a robust weakening of the thermocline feedback from the time period 1980-99 to the more recent time period 2000-10. This weakening is due to both a weakening of the zonally averaged wind stress response to eastern Pacific SST anomalies as well as a reduced thermocline slope response to basinwide zonal wind stress anomalies. The weakened response of zonal wind stress to SST anomalies is due to the cooler mean SST in the eastern equatorial Pacific that results in reduced mean convection and a westward shift in the ascending branch of the Walker circulation. The weakened thermocline slope response to zonal wind stress anomalies can be attributed to a smaller zonal wind fetch in the more recent time period due to ENSO-related wind anomalies being more confined to the western basin.

It should be noted that our analysis is based on a rather short time period, especially concerning P2. As individual events can develop differently due to reasons unrelated to background state changes (e.g., differences in stochastic forcing), longer, multidecadal time series of EP and CP El Niño regimes would be desirable to establish a clear relationship between changes in ENSO characteristics and the mean state. Lacking such long records, we can nonetheless make reasonable inferences using an ensemble of different ocean reanalyses products.

With these limitations in mind, our results are consistent with Fedorov and Philander (2000) who discuss the role of the tropical Pacific background state in affecting the character of ENSO. Stronger mean trade winds drive warm surface waters westward, which results in a deepening of the thermocline in the west and a shoaling in the east. According to their theory, stronger winds and shallower thermocline lead to colder SSTs in the east and a higher-frequency, more damped ENSO cycle as we observe during P2. Jin and Neelin (1993) arrived at similar conclusions in a different theoretical framework utilizing a simplified Zebiak-Cane model. Our results are also in agreement with recent studies by Choi et al. (2011), Hu et al. (2013), and Chung and Li (2013) that use different approaches to examine how the background state can affect the character of the ENSO cycle. As discussed in the introduction, they find that the recent increase in CP El Niños is linked to changes in the equatorial Pacific mean state, including stronger trade winds, stronger zonal SST gradients, and steeper equatorial thermocline slopes. Our results are, however, contrary to the findings of Ashok et al. (2007) and Yeh et al. (2009) that link the increased occurrence of CP El Niño events to weakened easterly winds and a flattening of the equatorial mean thermocline. They are also in contrast to the results of Borlace et al. (2013) that suggest a stronger thermocline feedback for epochs with stronger easterlies and steeper thermocline slope in their 1000-yr model simulation. A decrease in the thermocline response to atmospheric forcing has also been related to reduced stratification (Dewitte 2000; Thual et al. 2011, 2013). In agreement with Hu et al. (2013, see their Fig. 3), we find, however, that stratification in the eastern equatorial Pacific increased from $\mathrm{P} 1$ to $\mathrm{P} 2$ in the ocean reanalysis products since the main cooling there occurs right below the thermocline.

The recent predominance of $\mathrm{CP} \mathrm{El}$ Niños has been linked to a stronger zonal advective feedback (Kug et al. 2009; Chung and Li 2013). While we do not see a clear trend in the strength of the zonal advective feedback among the reanalysis products, its relative importance is enhanced as the thermocline feedback weakens from P1 to P2. It should be noted, however, that the BJ index calculated from variables averaged over the Niño-3 region mainly reflects behavior in the eastern equatorial Pacific. It might thus be expected that the zonal advective feedback is more important farther to the west. We made an attempt to account for changes in the central Pacific by calculating additional $\mathrm{BJ}$ index terms based on a Niño-3+ region that reaches farther to the west. As expected, for this larger region thermocline feedbacks are weaker and the zonal advective feedbacks are enhanced. However, otherwise the results were similar to those for the Niño-3-based index (i.e., a weakening of the thermocline feedback as well as the zonal advective feedback in most of the reanalysis products from P1 to P2).

As noted in the introduction, Barnston et al. (2012) found that ENSO forecast skill decreased during 2002-11 
compared to the previous 20 years. They ascribed this decrease to reduced predictability associated with weakeramplitude ENSO variations. The focus period of their study (2002-11) is essentially coincident with P2 as defined in our study (2000-10). Connecting these two studies, weaker-amplitude ENSO variations are consistent with a more damped ENSO cycle. Thus, we would infer that the reduced ENSO predictability identified by Barnston et al. (2012) is linked to the more frequent occurrence of CP El Niños and a reduction in positive thermocline feedbacks that we have documented in the first decade of the twenty-first century (see also McPhaden 2012).

Whether the change we observe in ENSO feedbacks and stability are due to natural variability or anthropogenic climate change is a matter of debate. For example, in response to greenhouse gas forcing over the next century, some climate models find enhanced ENSO variability while others predict reduced variability (Guilyardi et al. 2009; Collins et al. 2010). With regard to the shift in the location of maximum SST anomalies, Yeh et al. (2009) suggested that a weakening of the trade winds as part of a weakening of the Walker circulation due to global warming reduces upwelling and thus the thermocline feedback in the eastern equatorial Pacific, resulting in more CP El Niños. On the other hand, Newman et al. (2011) and Wittenberg (2009) argued that multidecade periods of more EP or more CP El Niños can occur due to intrinsic natural variations. Li et al. (2013) found natural decadal fluctuations in the ENSO cycle from a novel 700-yr-long tree ring-based ENSO reconstruction with anomalously high ENSO activity in the late twentieth century. Also Cobb et al. (2013) found from fossil coral reconstruction highly variable ENSO activity over the past 7000 years and that ENSO variance in the twentieth century was higher than average but not unprecedented. Even though our results are based on a short time period, they indicate that the decadal change in ENSO characteristics is consistent with the observed background state changes that are opposite to those expected from enhanced greenhouse gas forcing proposed by Yeh et al. (2009). Thus, we attribute the changes we have detected as the result of either natural decadal variability or external forcing that acts differently from that predicted by most climate models.

Changed ENSO characteristics affect the tropical Pacific, and because of atmospheric teleconnections they have large impacts on patterns of weather variability around the world. It is thus of critical importance to understand the underlying causes for the observed changes in the character of ENSO over the last 30 years. Our results suggest that a weakened thermocline feedback in association with decadal changes in the tropical
Pacific background state plays an important role in damping the ENSO cycle, coincident with the emergence of more frequent CP El Niños in the first decade of the 21 st century.

Acknowledgments. The authors like to thank three anonymous reviewers for their constructive comments. This research was performed while the first author held a National Research Council Research Associateship Award at NOAA/PMEL. We thank Simona Masina and Pierluigi Di Pietro for the INGV OI5 output and Armin Köhl for the GECCO2 output.

\section{REFERENCES}

An, S.-I., and B. Wang, 2000: Interdecadal change of the structure of the ENSO mode and its impact on the ENSO frequency. J. Climate, 13, 2044-2055.

Ashok, K., S. K. Behera, S. A. Rao, H. Weng, and T. Yamagata, 2007: El Niño Modoki and its possible teleconnection. J. Geophys. Res., 112, C11007, doi:10.1029/2006JC003798.

Balmaseda, M. A., A. Vidard, and D. L. T. Anderson, 2008: The ECMWF Ocean Analysis System: ORA-S3. Mon. Wea. Rev., 136, 3018-3034.

- K. Mogensen, and A. T. Weaver, 2013: Evaluation of the ECMWF ocean reanalysis system ORAS4. Quart. J. Roy. Meteor. Soc., 139, 1132-1161, doi:10.1002/qj.2063.

Barnston, A. G., M. K. Tippett, M. L. L'Heureux, S. Li, and G. D. DeWitt, 2012: Skill of real-time seasonal ENSO model predictions during 2002-11: Is our capability increasing? Bull. Amer. Meteor. Soc., 93, 631-651.

Battisti, D. S., and A. C. Hirst, 1989: Interannual variability in a tropical atmosphere-ocean model: Influence of the basic state, ocean geometry, and nonlinearity. J. Atmos. Sci., 46, 1687-1712.

Behringer, D., and Y. Xue, 2004: Evaluation of the global ocean data assimilation system at NCEP: The Pacific Ocean. Preprints, Eighth Symp. on Integrated Observing and Assimilation Systems for Atmosphere, Oceans, and Land Surface, Seattle, WA, Amer. Meteor. Soc., 2.3. [Available online at https://ams. confex.com/ams/pdfpapers/70720.pdf.]

Borlace, S., W. Cai, and A. Santoso, 2013: Multidecadal ENSO amplitude variability in a 1000 -yr simulation of a coupled global climate model: Implications for observed ENSO variability. J. Climate, 26, 9399-9407.

Carton, J. A., and B. S. Giese, 2008: A reanalysis of ocean climate using Simple Ocean Data Assimilation (SODA). Mon. Wea. Rev., 136, 2999-3017.

Choi, J., S.-I. An, J.-S. Kug, and S.-W. Yeh, 2011: The role of mean state on changes in El Niño's flavor. Climate Dyn., 37, 12051215, doi:10.1007/s00382-010-0912-1.

Chung, P.-H., and T. Li, 2013: Interdecadal relationship between the mean state and El Niño types. J. Climate, 26, 361-379.

Clark, A. J., S. van Gorder, and G. Colantuono, 2007: Wind stress curl and ENSO discharge/recharge in the equatorial Pacific. J. Phys. Oceanogr., 37, 1077-1091.

Cobb, K. M., N. Westphal, H. R. Sayani, J. T. Watson, E. Di Lorenzo, H. Cheng, R. L. Edwards, and C. D. Charles, 2013: 
Highly variable El Niño-Southern Oscillation throughout the Holocene. Science, 339, 67-70, doi:10.1126/science.1228246.

Collins, M., and Coauthors, 2010: The impact of global warming on the tropical Pacific Ocean and El Niño. Nat. Geosci., 3, 391397, doi:10.1038/NGEO868.

Dee, D. P., and Coauthors, 2011: The ERA-Interim reanalysis: Configuration and performance of the data assimilation system. Quart. J. Roy. Meteor. Soc., 137, 553-597.

Dewitte, B., 2000: Sensitivity of an intermediate ocean-atmosphere coupled model of the tropical Pacific to its oceanic vertical structure. J. Climate, 13, 2363-2388.

Fedorov, A. V., and S. G. Philander, 2000: Is El Niño changing? Science, 288, 1997-2002.

Giese, B. S., and S. Ray, 2011: El Niño variability in Simple Ocean Data Assimilation (SODA), 1871-2008. J. Geophys. Res., 116, C02024, doi:10.1029/2010JC006695.

Guilyardi, E., A. Wittenberg, A. Fedorov, M. Collins, C. Wang, A. Capotondi, G. J. van Oldenborgh, and T. Stockdale, 2009: Understanding El Niño in ocean-atmosphere general circulation models: Progress and challenges. Bull. Amer. Meteor. Soc., 90, 325-340.

Horii, T., I. Ueki, and K. Hanawa, 2012: Breakdown of ENSO predictors in the 2000s: Decadal changes of recharge/discharge-SST phase relation and atmospheric intraseasonal forcing. Geophys. Res. Lett., 39, L10707, doi:10.1029/ 2012GL051740.

Hu, Z.-Z., A. Kumar, H.-L. Ren, H. Wang, M. L'Heureux, and F.-F. Jin, 2013: Weakened interannual variability in the tropical Pacific Ocean since 2000. J. Climate, 26, 2601-2613.

Jin, F.-F., 1997: An equatorial ocean recharge paradigm for ENSO. Part I: Conceptual model. J. Atmos. Sci., 54, 811-829.

— , and J. D. Neelin, 1993: Modes of interannual tropical oceanatmosphere interaction-A unified view. Part I: Numerical results. J. Atmos. Sci., 50, 3477-3503.

—, S. T. Kim, and L. Bejarano, 2006: A coupled-stability index for ENSO. Geophys. Res. Lett., 33, L23708, doi:10.1029/ 2006GL027221.

Kessler, W. S., and M. J. McPhaden, 1995: Oceanic equatorial waves and the 1991-93 El Niño. J. Climate, 8, 1757-1774.

Kim, S. T., and F.-F. Jin, 2011a: An ENSO stability analysis. Part I: Results from a hybrid coupled model. Climate Dyn., 36 (7-8), 1593-1607, doi:10.1007/s00382-010-0796-0.

_, and _ 2011b: An ENSO stability analysis. Part II: Results from the twentieth and twenty-first century simulations of the CMIP3 models. Climate Dyn., 36 (7-8), 1609-1627, doi:10.1007/ s00382-010-0872-5

Köhl, A., and D. Stammer, 2008: Variability of the meridional overturning in the North Atlantic from the 50-yr GECCO state estimation. J. Phys. Oceanogr., 38, 1913-1930.

Kug, J.-S., F.-F. Jin, and S.-I. An, 2009: Two types of El Niño events: Cold tongue El Niño and warm pool El Niño. J. Climate, 22, 1499-1515.

Kumar, A., and Z.-Z. Hu, 2013: Interannual and interdecadal variability of ocean temperature along the equatorial Pacific in conjunction with ENSO. Climate Dyn., doi:10.1007/ s00382-013-1721-0.

Larkin, N. K., and D. E. Harrison, 2005: Global seasonal temperature and precipitation anomalies during El Niño autumn and winter. Geophys. Res. Lett., 32, L13705, doi:10.1029/ 2005GL022738.
Lee, T., and M. J. McPhaden, 2010: Increasing intensity of El Niño in the central-equatorial Pacific. Geophys. Res. Lett., 37, L14603, doi:10.1029/2010GL044007.

Li, J., and Coauthors, 2013: El Niño modulations over the past seven centuries. Nat. Climate Change, 3, 822-826, doi:10.1038/ nclimate1936.

Liebmann, B., and C. A. Smith, 1996: Description of a complete (interpolated) outgoing longwave radiation dataset. Bull. Amer. Meteor. Soc., 77, 1275-1277.

Lübbecke, J. F., and M. J. McPhaden, 2013: A comparative stability analysis of Atlantic and Pacific Niño modes. J. Climate, 26, 5965-5980.

Masina, S., P. Di Pietro, A. Storto, and A. Navarra, 2011: Global ocean re-analyses for climate applications. Dyn. Atmos. Oceans, 52, 341-366, doi:10.1016/j.dynatmoce.2011.03.006.

McPhaden, M. J., 2012: A 21st century shift in the relationship between ENSO SST and warm water volume anomalies. Geophys. Res. Lett., 39, L09706, doi:10.1029/2012GL051826.

—, S. E. Zebiak, and M. H. Glantz, 2006: ENSO as an integrating concept in Earth science. Science, 314, 1740-1745, doi:10.1126/ science. 1132588 .

- T. Lee, and D. McClurg, 2011: El Niño and its relationship to changing background conditions in the tropical Pacific Ocean. Geophys. Res. Lett., 38, L15709, doi:10.1029/2011GL048275.

Newman, M., S.-I. Shin, and M. A. Alexander, 2011: Natural variation in ENSO flavors. Geophys. Res. Lett., 38, L14705, doi:10.1029/2011GL047658.

Praveen Kumar, B., J. Vialard, M. Lengaigne, V. S. N. Murty, and M. J. McPhaden, 2012: TropFlux: Air-sea fluxes for the global tropical oceans-Description and evaluation. Climate Dyn., 38, 1521-1543, doi:10.1007/s00382-011-1115-0.

Ren, H., and F. Jin, 2013: Recharge oscillator mechanisms in two types of ENSO. J. Climate, 26, 6506-6523.

Reynolds, R. W., N. A. Rayner, T. M. Smith, D. C. Stokes, and W. Wang, 2002: An improved in situ and satellite SST analysis for climate. J. Climate, 15, 1609-1625.

Smith, N. R., 1995: An improved system for tropical ocean subsurface temperature analyses. J. Atmos. Oceanic Technol., 12, 850-870.

Stein, K., N. Schneider, A. Timmermann, and F.-F. Jin, 2010: Seasonal synchronization of ENSO events in a linear stochastic model. J. Climate, 23, 5629-5643.

Thual, S., B. Dewitte, S.-I. An, and N. Ayoub, 2011: Sensitivity of ENSO to stratification in a recharge-discharge conceptual model. J. Climate, 24, 4332-4349.

,,,--- S. Illig, and N. Ayoub, 2013: Influence of recent stratification changes on ENSO stability in a conceptual model of the equatorial Pacific. J. Climate, 26, 4790-4802.

Wakata, Y., and E. S. Sarachik, 1991: Unstable coupled atmosphereocean basin modes in the presence of a spatially varying basic state. J. Atmos. Sci., 48, 2060-2077.

Wittenberg, A. T., 2009: Are historical records sufficient to constrain ENSO simulations? Geophys. Res. Lett., 36, L12702, doi:10.1029/2009GL038710.

Yeh, S.-W., J.-S. Kug, B. Dewitte, M.-H. Kwon, B. Kirtman, and F.-F. Jin, 2009: El Niño in a changing climate. Nature, 461, 511-514, doi:10.1038/nature08316.

Zhang, S., M. J. Harrison, A. Rosati, and A. T. Wittenberg, 2007: System design and evaluation of coupled ensemble data assimilation for global oceanic climate studies. Mon. Wea. Rev., $\mathbf{1 3 5}, 3541-3564$ 